\title{
Simultaneous bilateral spontaneous pneumomediastinum and pneumothorax in a cannabis user
}

\author{
Sevilay Vural, ${ }^{1}$ Ahmet Tuğrul Zeytin, ${ }^{2}$ Şeyhmus Kaya, ${ }^{2}$ Barış Öztürk ${ }^{2}$ \\ ${ }^{1}$ Department of Emergency Medicine, Bozok University, Yozgat; ${ }^{2}$ Department of Emergency Medicine, \\ Eskişehir State Hospital, Eskişehir, Turkey
}

\begin{abstract}
Cannabis - the most commonly used illegal drug - also has some medical applications. Cannabis is being legalised more and more in the Western world, however it is not a safe substance as many people think. It can cause detrimental acute and chronic lung injuries such as bullous lung disease, chronic bronchitis, chronic obstructive pulmonary disease, pneumothorax, pneumomediastinum, pulmonary emphysema. A clear mechanism for acute pulmonary pathologies has not been established, but pneumothorax and/or pneumomediastinum can be considered as a typical presentation in cannabis users. We present a cannabis user case with simultaneous pneumomediastinum and bilateral spontaneous pneumothorax.
\end{abstract}

\section{Introduction}

A build-up of air that accumulates in the pleural space is called a pneumothorax. If air is in the mediastinum, then it is known as pneumomediastinum. Simultaneous bilateral spontaneous pneu-

Correspondence: Sevilay Vural, Department of Emergency Medicine, Bozok University, Şeyh Osman Mahallesi, Adnan Menderes Blv. No 44, Acil Tip Ana Bilim Dalı, 66100 Yozgat Merkez/Yozgat, Turkey.

Tel.: +90506.366.92.27 - Fax: +90.354.217.10.72.

E-mail: sevilayvural@yahoo.com

Key words: Cannabis; Marijuana; Spontaneous bilateral pneumothorax; Pneumomediastinum.

Contributions: the authors contributed equally.

Conflict of interest: the authors declare no potential conflict of interest.

Funding: none.

Conference presentation: part of this paper was presented at the 11th National Emergency Medicine Congress \& 2nd Intercontinental Emergency Medicine Congress \& 2nd International Critical Care and Emergency Medicine Congress, 16-19 April 2015, Antalya, Turkey.

Received for publication: 29 October 2018.

Revision received: 28 December 2018.

Accepted for publication: 24 January 2019.

This work is licensed under a Creative Commons Attribution 4.0 License (by-nc 4.0).

CCopyright S. Vural et al., 2019

Licensee PAGEPress, Italy

Emergency Care Journal 2019; 15:7890

doi:10.4081/ecj.2019.7890 mothorax (SBSP) is rarely observed compared to unilateral pneumothorax. The limited literatural incidence for SBSP is approximately 1 to $1.3 \%$ of all spontaneous pneumothorax. ${ }^{1}$ The combined presence of an accompanying pneumomediastinum, which is generally a benign condition, reduces this incidence even more and also increases the medical severity. It is well established and documented that tobacco use is a risk factor for spontaneous pneumothorax. ${ }^{2}$ Some studies suggest that cannabis (also known as marijuana) is also a risk factor for spontaneous pneumothorax, but this link is not as obvious as that with tobacco., ${ }^{3,4}$ The use of cannabis combined with tobacco makes it difficult to detect the isolated effect of cannabis on pneumothorax or any other kinds of lung injuries. Cannabis is the most commonly used illegal drug in many parts of the world, especially by the young population. It is recognised that there are many different ways of consuming it, but it is mostly used by smoking it, either in an unmixed form or mixed with tobacco. During smoking cannabis, users often perform a unique method of inhalation (deep forced inspirations and high volume breath-holdings), very similar to the Valsalva manoeuvre.

\section{Case Report}

A 23-year-old male presented to the emergency department with chest pain and severe dyspnea. The patient had normal height $(175 \mathrm{~cm})$ and weight $(74 \mathrm{~kg})$. His medical history was irrelevant to the condition as he wasn't a smoker and claimed no trauma history. The family history did not contain any indications for cardiovascular or lung disease. The cardiovascular exam did not indicate anything significant, but his respiratory exam revealed decreased breathing sounds bilaterally and subcutaneous emphysema around the neck and shoulders. There was no evidence of trauma that could have caused this. His initial vital signs showed a blood pressure of $110 / 75 \mathrm{mmHg}$, a heart rate of $128 / \mathrm{min}$, respiratory rate of 26 breaths per minute and fingertip $\mathrm{O}_{2}$ saturation of $93 \%$. An ECG was carried out and found to be normal. A posteroanterior chest Xray and computed tomography scan of his thorax were requested while supplemental oxygen therapy was started. Bilateral spontaneous pneumothorax and pneumomediastinum with subcutaneous emphysema were identified in radiologic images (Figures 1 and 2).

After the second detailed investigation, the patient informed us that he was an active marijuana user and had been so for about 56 years. He denied any other drug use. His method of consumption of marijuana was by mixing it with tobacco and smoking the mixture. He had coughed two or three times during the smoking of marijuana when he noticed the dyspnea. His toxicology screen was found to be only positive for tetrahydrocannabinol, the principal active compound in marijuana, which seemed to confirm his drug use. The thoracic surgery consultation determined that there was no need for surgery, tube thoracotomy or chemical pleurodesis, so he was transferred to the thoracic surgery ward for observation. He was subsequently discharged on the $4^{\text {th }}$ day without the further need of medical intervention. 


\section{Discussion}

Tobacco smoke has well-documented dangerous and carcinogenic effects on human body, however the literature researches on cannabis smoke is mainly focused on psychological effects rather than physiological consequences. The biggest problem experienced by the researchers who studied the physiological effects of cannabis, was the consumption of cannabis mixed with tobacco, hence the difficulty of evaluating its effects as an isolated compound. ${ }^{3}$ Lutchmansingh et al. reported fewer lung functional changes compared to a tobacco user, but more bullous lung disease

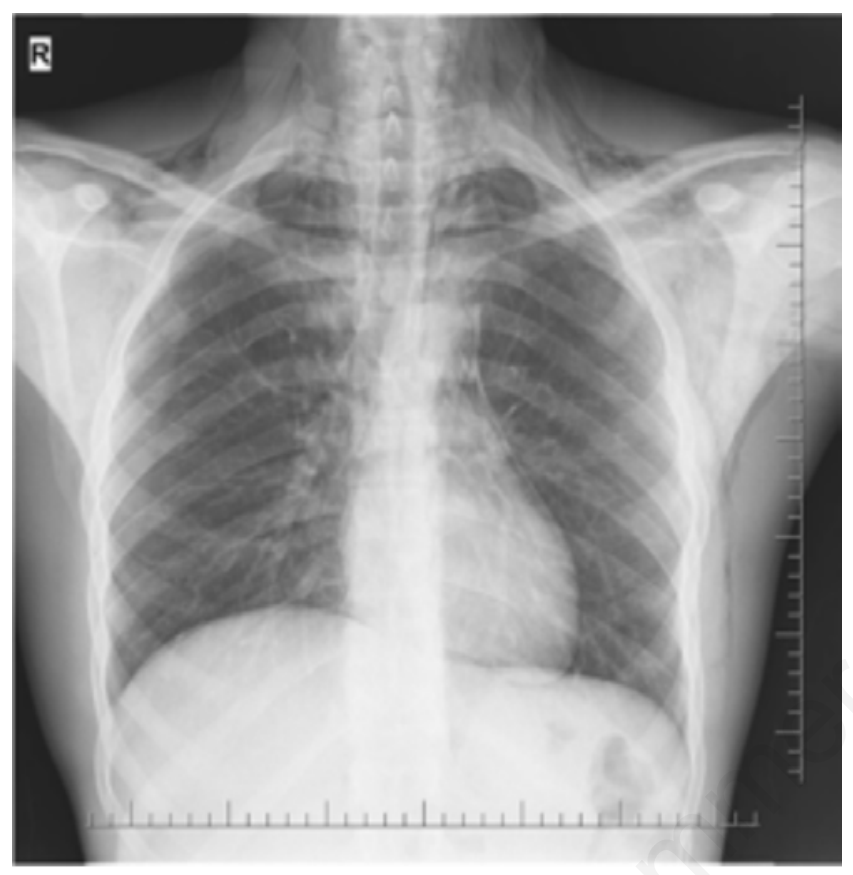

Figure 1. Posteroanterior chest X-ray of the patient.

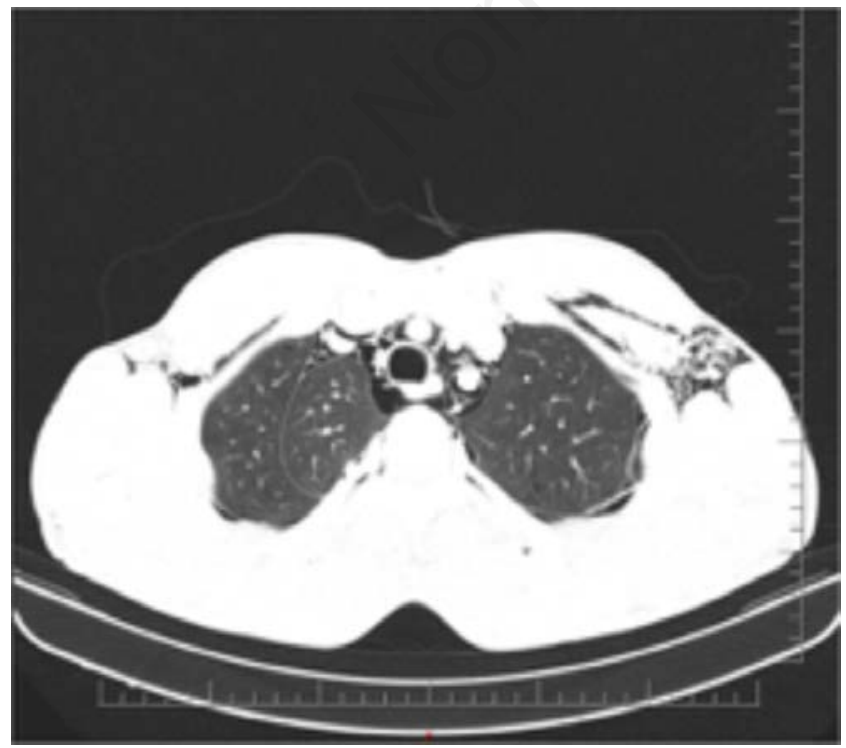

Figure 2. Thorax computed tomography of the patient. and spontaneous pneumothorax tendency in cannabis users compared to non-smoking population. ${ }^{5}$ Some recent studies suggested that there is relationship between smoking cannabis and lung cancer but the evidence is not enough to make an assumption yet. ${ }^{6,7}$

A number of cases with pneumothorax and/or pneumomediastinum in cannabis users have been described in the literature which suggest a cause-effect relationship but larger and more cohort studies are needed to clarify the association..$^{8-12}$ One of the recent studies which had a relatively larger cohort population, showed that the combination of smoking of tobacco and cannabis significantly increases the risk of having a primary spontaneous pneumothorax in young men compared to both non-smokers and daily tobacco only smokers. ${ }^{3}$

When a spontaneous pneumothorax occurs in a cannabis smoker, the possibility of a secondary spontaneous pneumothorax should be considered. ${ }^{11}$ The most commonly attributed mechanism for primary pneumothorax and/or pneumomediastinum is the smoking technique. . $^{8,10}$ The suggested mechanism is barotrauma of coughing during breath-holding periods which may cause alveoli to overdistend and rupture. On the other hand, in the presence of emphysema due to chronic lung injury, they can be considered as secondary spontaneous pneumothorax. Barotrauma mechanism seems to be the most likely scenario in our case. Because our case doesn't have chronic lung disease history or any emphysematous changes on radiologic images and his history reveals presence of coughing when the status of dyspnea emerged.

\section{Conclusions}

Simultaneous pneumomediastinum and bilateral spontaneous pneumothorax are rare clinical conditions. There is a potential association between cannabis and spontaneous pneumothorax and/or pneumomediastinum, whether or not it is due to barotrauma or chronic lung injury. These unique presentation types of cannabis abusers should be identified particularly by emergency physicians and thoracic surgeons. A full drug history should be obtained from patients diagnosed as spontaneous pneumothorax or pneumomediastinum, especially in young population.

\section{References}

1. Hoyos de A, Fry WA. Pneumothorax. In: Shields TW, LoCicero J, Reed CE, Feins H, ed. General thoracic surgery. 7th ed. Philadelphia: Lippincott Williams \& Wilkins; 2009. pp 739-761.

2. Haynes D, Baumann MH. Pleural controversy: aetiology of pneumothorax. Respirology 2011;16:604-10.

3. Hedevang Olesen W, Katballe N, Sindby JE, et al. Cannabis increased the risk of primary spontaneous pneumothorax in tobacco smokers: a case-control study. Eur J Cardiothorac Surg 2017;52:679-85.

4. Gill A. Bong lung: regular smokers of cannabis show relatively distinctive histologic changes that predispose to pneumothorax. Am J Surg Pathol 2005;29:980-2.

5. Lutchmansingh D, Pawar L, Savici D. Legalizing cannabis: a physician's primer on the pulmonary effects of marijuana. Curr Respir Care Rep 2014;3:200-5.

6. Imtiaz S, Shield KD, Roerecke M, et al. The burden of disease attributable to cannabis use in Canada in 2012. Addiction 2016;111:653-62. 
7. Kreuter M, Nowak D, Rüther T, et al. Cannabis - Position Paper of the German Respiratory Society (DGP). Pneumologie 2016;70:87-97.

8. Miller WE, Spiekerman RE, Hepper NG. Pneumomediastinum resulting from performing Valsalva manoeuvres during marijuana smoking. Chest 1972;62:233-4.

9. Shah A, Paramlal M. The importance of an illicit drug history in the evaluation of suspected spontaneous pneumothorax. BMJ Case Rep 2011;bcr0120113693.
10. Goodyear K, Laws D, Turner J. Bilateral spontaneous pneumothorax in a cannabis smoker. J R Soc Med 2004;97:435-6.

11. Chardon ML, Dalphin JC, Degano B. [Pneumothorax in young cannabis smokers: A propos of three cases]. Rev Mal Respir 2018;35:556-61.

12. Birrer RB, Calderon J. Pneumothorax, pneumomediastinum, and pneumopericardium following Valsalva's maneuver during marijuana smoking. N Y State J Med 1984;84:619-20. 